\title{
Risk of leukemia in first degree relatives of patients with nonsyndromic cleft lip and palate
}

Eduardo GONÇALVES(a)

Daniella Reis Barbosa MARTELLI(a)

Ricardo Della COLETTA ${ }^{(b)}$

Alexandre Rezende VIEIRA(c)

Antônio Prates CALDEIRA ${ }^{(a)}$

Hercílio MARTELLI JÚNIOR(a)

\footnotetext{
(a) Health Science Programme, Universidade Estadual de Montes Claros - UNIMONTES, Montes Claros, MG, Brazil.

(b) Department of Oral Diagnosis, School of Dentistry, Universidade Estadual de Campinas - UNICAMP, Piracicaba, SP, Brazil.

(c) Department of Oral Biology, School of Dental Medicine, University of Pittsburgh, Pittsburgh, PA, United State of America.
}

Declaration of Interests: The authors certify that they have no commercial or associative interest that represents a conflict of interest in connection with the manuscript.

Corresponding Author:

Herćlio Martelli Júnior

E-mail: hmjunior2000@yahoo.com

DOI: 10.1590/1807-3107BOR-2014.vol28.0056

Submitted: Jul 03, 2014

Accepted for publication: Jul 15, 2014

Last revision: Sep 17, 2014

\begin{abstract}
The aim of this study was to determine the frequency of leukemia in parents of patients with nonsyndromic cleft lip and/or cleft palate (NSCL/P). This case-control study evaluated first-degree family members of 358 patients with NSCL/P and 1,432 subjects without craniofacial alterations or syndromes. Statistical analysis was carried out using Fisher's test. From the 358 subjects with NSCL/P, 3 first-degree parents had history of leukemia, while 2 out of 1,432 subjects from the unaffected group had a family history of leukemia. The frequency of positive family history of leukemia was not significantly increased in first-degree relatives of patients with NSCL/P.
\end{abstract}

Keywords: Leukemia; Cleft Lip; Cleft Palate; Epidemiology; Neoplasms.

\section{Introduction}

Cancer and birth defects may share factors that influence risk, being of genetic and/or environmental origin. ${ }^{1}$ Furthermore, a malformation may involve physiological changes or changes in lifestyle that might in turn affect cancer risk. ${ }^{2}$ Nonsyndromic cleft lip and/or cleft palate (NSCL/P, OMIM \#119530) is the most common craniofacial birth defect in humans, with a global prevalence ranging from 1:500 to 1:2,500 live births, ${ }^{3}$ depending on ancestry, geographic residential location, maternal age and prenatal exposures, and socioeconomic status. ${ }^{4}$

In recent years, epidemiological evidence has shown the association of cancer with NSCL/P in several populational studies. ${ }^{5,6,78}$ It has been proposed that cancer and congenital malformations such as NSCL/P may occasionally have a common etiology. The underlying concept is that the same genes can act in normal and also malignant development. ${ }^{1,7}$ The association between NSCL/P and leukemia remains unclear and there are no studies evaluating this association in Brazil.

The aim of the current study was to determine the frequency of leukemia in parents of subjects with NSCL/P in a Brazilian population.

\section{Methodology}

After proper local and Center for Rehabilitation of Craniofacial Anomalies, Minas Gerais State, Brazil, Institutional Review Board approval, we conducted a case-control study which was approved by the Ethics Committee on Institutional Research \#259/2009, for the 
time period of 2010-2012, evaluating 358 patients with NSCL/P, seen at a referral center for the treatment of craniofacial deformities, and 1,432 patients without craniofacial alterations or any syndrome (control group), identified randomly from the General Clinics of the Dental School at the Universidade de Alfenas, Minas Gerais State, Brazil. We obtained information concerning the gender, age and family history of leukemia in first-degree relatives (mother, father and siblings) for both groups. No participants declined to respond to the questionnaire. The t-test assessed whether the means of age for the two groups were statistically different from each other. Statistical analyses were also carried out using Fisher's exact test (expected frequency values fell below 5) and the odds ratio $(\mathrm{OR})$ with its $95 \%$ confidence interval $(95 \% \mathrm{CI})$ to estimate the magnitude of the risk. Values with $p<0.05$ were considered statistically significant.

\section{Results}

The average age of the cases diagnosed with NSCL/P was 13.57 years. The average age of the control group was 14.22 years. There was no difference of age distribution between affected and unaffected women $(p=0.55)$. From the 358 subjects with NSCL/P, 3 first-degree relatives had a positive family history of leukemia, while 2 of the 1,432 subjects from the unaffected group had a positive family history of leukemia (Table 1). The Fisher exact test showed $p=0.057$ and $\mathrm{OR}=6.04(95 \% \mathrm{CI}=0.69-72.49)$. Thus, in the present study the frequency of leukemia was not significantly increased in the first-degree relatives of patients with NSCL/P.

\section{Discussion}

In the present study the frequency of positive family history of leukemia was not significantly increased in first-degree relatives of patients with NSCL/P. Similarly, the risk of breast cancer in families with patients affected by NSCL/P was not increased. ${ }^{9}$
On the other hand, a study showed a family history of cancer (colon, brain, leukemia, breast, prostate, skin, lung and liver) more often in relatives of NSCL/P compared to the control group. Recently, we evaluated the risk of NSCL/P in relatives of women with breast cancer in the Brazilian population and found no association between the two conditions. ${ }^{5,10}$

Another study ${ }^{11}$ showed that among cancer survivors with a family member with NSCL/P, there was an apparent excess of testicular cancer and melanoma in comparison with the cancer survivors with no family history of NSCL/P. These preliminary results suggest a common etiologic background for cancer and NSCL/P.

A recent study assessed the frequency of NSCL/P in families of children diagnosed with leukemia. The results of this study provide suggestive evidence that families with children diagnosed with leukemia report a family history of NSCL/P more often than families without cases of pediatric cancer. ${ }^{7}$

The association between cancer and NSCL/P could be attributable to both genetic factors and/or familial environmental factors that are both teratogenic and carcinogenic. ${ }^{9}$ Another possibility could be that having a cleft leads to social marginalization and changes in lifestyle that may be predisposed to an individual and their family to cancer (i.e. smoking, high alcohol use, etc.). ${ }^{12}$

\section{Conclusion}

To investigate the relationship between malformations and malignancies is important, as it is speculated that they might have common causes. In the present study the frequency of a positive family history of leukemia was not significantly increased in first-degree relatives of patients with NSCL/P. The main limitation of our study was the sample size. Studies with larger samples and molecular analyses are needed for a better understanding between NSCL/P and leukemia.

Table 1. Risk of leukemia in first-degree relatives of patients with nonsyndromic cleft lip and palate (NSCL/P)

\begin{tabular}{lccc}
\hline Groups & No of subjects & Positive history of leukemia & OR $(95 \% C l) / p$ value \\
Control & 1,432 & 2 & Reference \\
NSCL/P & 358 & 3 & $6.04(0.69-72.49) / 0.057$ \\
\hline
\end{tabular}




\section{Acknowledgments}

This work was supported by grants from Fundação de Amparo à Pesquisa do Estado de Minas Gerais -FAPEMIG,

\section{References}

1. Popoff DAV, Coelho MP, Martelli DRB, Saini R, Coletta RD, Martelli Júnior H. Non-syndromic oral clefts and risk of cancer: a systematic review. Dent 3000. 2013 Jan;1(1):1-7.

2. Bjorge T, Cnattingius S, Lie RT, Tretli S, Engeland A. Cancer risk in children with birth defects and in their families: a population based cohort study of 5.2 million children from Norway and Sweden. Cancer Epidemiol Biomarkers Prev. 2008 Mar;17(3):500-6.

3. Dixon MJ, Marazita ML, Beaty TH, Murray JC. Cleft lip and palate: understanding genetic and environmental influences. Nat Rev Genet. 2011 Mar;12(3):167-78.

4. Martelli DRB, Bonan PR, Soares MC, Paranaíba LR, Martelli Júnior H. Analysis of familial incidence of non-syndromic cleft lip and palate in a Brazilian population. Med Oral Patol Oral Cir Bucal. 2010 Nov 1;15(6):898-901.

5. Menezes R, Marazita ML, McHenry TG, Cooper ME, Bardi K, Brandon C, et al. AXIS inhibition protein 2, orofacial clefts and a family history of cancer. J Am Dent Assoc. 2009 Jan;140(1):80-4.

6. Jindal A, Vieira AR. Family history of cleft lip and palate in subjects diagnosed with leukemia. Am J Med Genet A. 2012 Mar;158A(3):678-9.
Minas Gerais, Brazil and the Conselho Nacional de Desenvolvimento Científico e Tecnológico-CNPq, Brasília, Brazil. Procad/Casadinho-Capes-CNPq.

7. Vieira AR, Khaliq S, Lace B. Risk of cancer in relatives of children born with isolated cleft lip and palate. Am J Med Genet A. 2012 Jul;158A(6):1503-4.

8. Lima LS, Silvério MO, Swerts MSO, Aquino SN, Martelli DRB, Martelli Júnior $\mathrm{H}$. Frequency of cancer in first-degree relatives of parents with cleft lip and/or palate in the Brazilian population. Braz Dent J. 2013 Jun;24(3):200-3.

9. Dietz A, Pedersen DA, Jacobsen R, Wehby GL, Murray JC, Christensen K. Risk of breast cancer in families with cleft lip and palate. Ann Epidemiol. 2012 Jan;22(1):37-42.

10. Martelli DRB, Vieira AR, Fonseca AT, Coletta RD, Soares PBM, Martelli-Júnior H. Risk of nonsyndromic cleft lip and palate in relatives of women with breast cancer. Am J Med Genet A. 2014 Jan;164A(1):270-1.

11. Taioli E, Ragin C, Robertson L, Linkov F, Thurman NE, Vieira AR. Cleft lip and palate in family members of cancer survivors. Cancer Invest. 2010 Nov;28(9):958-62.

12. Bille C, Winther JF, Bautz A, Murray JC, Olsen J, Christensen $\mathrm{K}$. Cancer risk in persons with oral cleft - a population-based study of 8,093 cases. Am J Epidemiol. 2005 Jun 1;161(11):1047-55. 